\title{
Alfabetismo funcional: Referências conceituais e metodológicas para a pesquisa
}

\author{
Vera Masagão Ribeiro *
}

\begin{abstract}
RESUMO: O artigo discorre sobre o alfabetismo funcional, conceito que se refere à condição de pessoas ou sociedades que utilizam a leitura e a escrita. Recupera as origens do conceito e suas diversas aplicações, inclusive servindo a concepções teóricas divergentes. Aponta os principais problemas teóricos e metodológicos implicados na pesquisa sobre o tema. Afirma as tendências mais atuais no campo, que consideram o alfabetismo como fenômeno multidimensional e a importância de se considerarem os contextos práticos e ideológicos em que realizam os usos da leitura e da escrita. Descreve, em linhas gerais, as opões metodológicas de um estudo sobre o tema que vem sendo realizado na América Latina, do qual participa uma equipe de pesquisadores brasileiros.
\end{abstract}

Palavras-chave: Alfabetização de adultos, analfabetismo funcional, educação de adultos, leitura, linguagem escrita

Analfabetismo é uma palavra utilizada no português corrente para designar a condição daqueles que não sabem ler e escrever; já seu antônimo afirmativo, alfabetismo, mesmo já tendo sido dicionarizado, ainda soa estranho aos falantes do idioma. Comentando essa curiosidade semântica, Magda B. Soares (1995) observa que o mesmo fato já ocorrera com o termo literacy, do inglês, que só passou a ser correntemente utilizado no final do século XIX, mais de dois séculos depois do surgimento do termo illiteracy, talvez porque a necessidade de compreender a condição dos que sabem ler e escrever tenha aparecido mais tardiamente na

* Assessora de Acão Educativa, Assessoria, Pesquisa e Informação. Doutoranda no programa de pós-graduação em Filosofia e História da Educação da PUC-SP. 
História, quando se tornaram mais complexas e variadas as demandas sociais relacionadas ao uso da linguagem escrita. Neste artigo, o termo alfabetismo é utilizado com o mesmo sentido de literacy, designando a condição de pessoas ou grupos que não apenas sabem ler e escrever, mas que, também, como propõe Soares, utilizam a leitura e a escrita, incorporam-na em seu viver, transformando por isso sua condição. ${ }^{1}$

\section{A origem dos conceitos de analfabetismo e alfabetismo funcional}

O termo alfabetismo funcional foi cunhado nos Estados Unidos na década de 1930 e utilizado pelo exército norte-americano durante a Segunda Guerra, indicando a capacidade de entender instruções escritas necessárias para a realização de tarefas militares (Castell, Luke \& MacLennan 1986). A partir de então, o termo passou a ser utilizado para designar a capacidade de utilizar a leitura e a escrita para fins pragmáticos, em contextos cotidianos, domésticos ou de trabalho, muitas vezes colocado em contraposição a uma concepção mais tradicional e acadêmica, fortemente referida a práticas de leitura com fins estéticos e à erudição. Em alguns casos, o termo analfabetismo funcional foi utilizado também para designar um meio termo entre o analfabetismo absoluto e o domínio pleno e versátil da leitura e da escrita, ou um nível de habilidades restrito às tarefas mais rudimentares referentes à "sobrevivência" nas sociedades industriais. Há ainda um conjunto de fenômenos relacionados que podem ser associados ao termo analfabetismo funcional, por exemplo, o analfabetismo por regressão, que caracterizaria grupos que, tendo alguma vez aprendido a ler e escrever, devido ao não uso dessas habilidades, retornam à condição de analfabetos. Especialmente na França, o termo iletrisme foi utilizado para caracterizar populações que, apesar de terem realizado as aprendizagens correspondentes, não integram tais habilidades aos seus hábitos, ou seja, em sua vida diária não lêem nem escrevem, independentemente do fato de serem capazes de fazê-lo ou não.

$\mathrm{Na}$ literatura americana, o sentido mais corrente do termo é aquele que referencia o alfabetismo funcional às basic skills, ou competências funcionais. Kirsch \& Julgeblut (1986) e Flecha et al. (1993) referem-se, como fonte importante para essa abordagem da temática, a programa de pesquisa desenvolvido na Universidade do Texas desde 1973, sob a denominação Adult Performance Level Project (ALP). Através de metodologias quantitativas e qualitativas, esse programa visa definir as competências funcionais necessárias ao desempenho satisfatório em contextos socioculturais 
determinados. Ao lado da leitura, da escrita e do cálculo, o programa considera como competências funcionais a linguagem oral, a informática, a resolução de problemas e as habilidades interpessoais aplicadas a contextos como a economia doméstica, a saúde, o trabalho, os recursos comunitários, as leis e o governo.

Uma característica marcante desse enfoque é a tentativa de ir além de uma concepção acadêmica da alfabetização, que a limita ao desempenho de tarefas tipicamente escolares. Investigando o nível e o tipo de competências necessárias para que os indivíduos possam se desenvolver no seu contexto sociocultural, tal perspectiva abre, inclusive, a possibilidade de se questionar a adequação dos currículos escolares com relação às demandas da sociedade. Permite ainda que se amplie a compreensão sobre os problemas relativos ao analfabetismo, uma vez que o não-domínio suficiente das habilidades pode ser associado não apenas a deficiências dos sistemas educativos, mas a questões mais amplas como as características do mercado de trabalho e dos meios de comunicação de massa ou a distribuição social das oportunidades de desenvolvimento cultural. Tal perspectiva de análise pode informar, portanto, tanto as políticas de educação formal quanto as de educação não formal de jovens e adultos e as políticas culturais de forma geral. Flecha et al. (1993) comentam que, não por acaso, o conceito de analfabetismo funcional originou-se nos Estados Unidos, onde a vertente não-escolar da educação de adultos, especialmente aquela voltada ao desenvolvimento comunitário, se desenvolveu com muita vitalidade teórica e prática.

Relacionada a essa orientação não escolarizante, outra característica do enfoque do alfabetismo como competência funcional é a consideração da natureza multidimensional do fenômeno. Nos Estados Unidos, correntes educacionais tecnicistas disseminaram pacotes instrucionais dedicados à alfabetização que se propõem a administrar o ensino de forma científica, graduando a complexidade das aprendizagens e oferecendo, como complemento, testes padronizados para avaliação e controle do processo. Esses testes padronizados pressupõem uma concepção da leitura como um conjunto de sub-habilidades discretas que, somando-se umas às outras seqüencialmente, compõem uma habilidade genérica de leitura, passível de ser aplicada a qualquer contexto (Anderson 1995). Organizando sub-habilidades numa escala única de dificuldades e selecionado um ponto qualquer dessa escala como diferencial, os indivíduos poderiam, a partir dela, ser classificados genericamente como alfabetizados ou analfabetos. Na década de 1980, tal concepção do alfabetismo foi fortemente questionada por um amplo conjunto de estudos que evidenciaram a natureza sociocultural das práticas de leitu- 
ra e escrita, enfocando seu estudo a partir de contextos específicos (Scribner \& Cole 1981; Heath 1986; Cook-Gumperz 1991). Tais estudos evidenciam uma grande variedade de práticas de alfabetismo, condicionadas tanto pela diversidade dos materiais de leitura quanto de propósitos a partir dos quais os leitores abordam os textos. Grandes pesquisas sobre o alfabetismo/analfabetismo, realizadas nas últimas décadas, abandonam a tentativa de estabelecer uma escala única de habilidades em prol do estabelecimento de conjuntos de tarefas socialmente relevantes, nas quais usos de materiais impressos ou escritos podem estar implicados. Mais do que a definição de sub-habilidades que comporiam habilidades de leitura ou de escrita genéricas, esses estudos procuram investigar a capacidade dos indivíduos de aplicar essas habilidades para atingir metas específicas, socialmente significativas.

\section{Os usos do conceito}

A ampla disseminação do termo analfabetismo funcional em âmbito mundial deveu-se basicamente à ação da Unesco, que adotou o termo na definição de alfabetização que propôs, em 1978, visando padronizar as estatísticas educacionais e influenciar as políticas educativas dos países-membros. A definição de alfabetização que a Unesco propusera em 1958 fazia referência à capacidade de ler compreensivamente ou escrever um enunciado curto e simples relacionado à sua vida diária. Vinte anos depois, a mesma Unesco proporia outra definição, qualificando a alfabetização de funcional quando suficiente para que os indivíduos possam inserir-se adequadamente em seu meio, sendo capazes de desempenhar tarefas em que a leitura, a escrita e o cálculo são demandados para seu próprio desenvolvimento e para o desenvolvimento de sua comunidade. ${ }^{2} \mathrm{O}$ qualitativo funcional insere a definição do alfabetismo na perspectiva do relativismo sociocultural. Tal definição já não visa limitar a competência ao seu nível mais simples (ler e escrever enunciados simples referidos à vida diária), mas abrigar graus e tipos diversos de habilidades, de acordo com as necessidades impostas pelos contextos econômicos, políticos ou socioculturais.

O apelo do termo analfabetismo funcional nos fóruns internacionais pode ser atribuído a essa polissemia de sua definição. Para os países desenvolvidos, que já não enfrentavam problemas relativos ao analfabetismo absoluto, tendo universalizado a educação básica, o conceito pôde servir para problematizar tanto a qualidade e a adequação do 
ensino oferecido pela escola, quanto para postular o valor da educação não-formal e da educação continuada. Na América Latina, onde ocorreu, nas décadas de 1970 e 1980, uma importante expansão dos sistemas de ensino elementar, o termo pôde servir também de referência para caracterizar a situação de uma grande parte da população que, apesar de ter tido acesso à escola, não conseguiu completar a educação básica, seja pela precariedade do ensino oferecido, seja pela precariedade das condições socioeconômicas a que se encontrava submetida.

Reconhecendo a dificuldade de se estabelecer com precisão quais seriam as demandas referentes à alfabetização colocadas pelas mais distintas realidades nacionais e regionais, assim como os problemas envolvidos em estabelecer índices quantitativos que permitissem comparações válidas, a própria Unesco sugeriu que se tomasse como indicador do nível de alfabetismo de países ou regiões um determinado número de anos de escolarização. A variância no número de anos de estudo considerado como suficiente em diferentes regiões atesta a maleabilidade do conceito; Castell, Luke e MacLennan (1986) reportam que, no Canadá, análises de dados censitários tomam nove anos de escolaridade formal como indicador do alfabetismo funcional; em documentos oficiais do governo espanhol, comentados por Flecha et al. (1993), aparece a referência a seis anos de escolaridade, enquanto nos países de Terceiro Mundo, o mais comum é identificar o alfabetismo funcional a apenas três ou quatro anos de estudo (Lodoño 1991). Certamente, essa variância no número de anos de escolaridade considerados como mínimo necessário não deriva, necessariamente, de diferentes graus de exigências impostos pelos diferentes contextos, mas, principalmente, das metas educacionais consideradas como factíveis para os países, de acordo com seu nível de desenvolvimento socioeconômico. Não podemos perder de vista que o papel desempenhado internacionalmente pela Unesco é, principalmente, de influência política e não de caráter científico.

A flexibilidade do conceito também deu margem a interpretações antagônicas do ponto de vista ideológico. Comentando documentos produzidos pelo Seminário Internacional de Persepolis, promovido pela Unesco em 1975, Street (1984) identifica interpretações antagônicas que se abrigavam sob o mesma definição proposta pela Unesco. Para uns, a funcionalidade da alfabetização dizia respeito, principalmente, à formação de mão-de-obra apta a adaptar-se às exigências da modernização econômica, para outros, a funcionalidade deveria ser interpretada como adequação das iniciativas de alfabetização aos interesses da população 
pobre, oprimida ou marginalizada, devendo, nesse sentido, visar à transformação das estruturas políticas e econômicas e não à adaptação dos indivíduos a elas. Soares (1992) identifica esse primeiro enfoque da natureza social da alfabetização como sua versão fraca, progressista ou liberal e a última como sua versão forte, radical ou revolucionária.

Em Educación, Comunicación y Lenguaje, Isabel Infante (1983) analisa como esses diferentes enfoques teóricos se traduzem em diferentes práticas alfabetizadoras, tomando como exemplo duas iniciativas de grande influência em âmbito mundial. Analisa o Programa Experimental Mundial de Alfabetização, nitidamente filiado às teorias da modernização de corte economicista. O Programa, promovido pela Unesco, e aplicado em 11 países do Terceiro Mundo, foi planejado como experimento da hipotética correlação entre alfabetização e desenvolvimento. Por meio de uma alfabetização funcional, ligada às necessidades mais imediatas dos adultos analfabetos, esperava-se provocar mudanças atitudinais associadas à modernização. Destacando um rol de resultados mensurados em avaliação do programa, onde predomina uma lógica de tipo individualista de aproveitamento de recursos e adaptação ao mercado de trabalho, a autora demonstra em que medida o conceito de desenvolvimento é limitado a uma perspectiva economicista e capitalista. Como contraponto a esse enfoque, Infante analisa os programas de alfabetização de adultos de inspiração freireana, que concebem o desenvolvimento a partir de esferas microssociais, nas quais os próprios alfabetizandos, ampliando sua consciência por meio da aprendizagem da leitura e do diálogo, poderiam definir os caminhos do desenvolvimento que correspondiam a seus anseios.

A ênfase nas demandas de natureza econômica, especialmente aos ditames do mercado de trabalho, é uma característica que ainda se pode identificar na fundamentação de estudos mais atuais de grande influência, como o de Kirsch e Julgeblut (1986). Isso não justifica, entretanto, que o enfoque do alfabetismo como competência funcional seja necessariamente limitado a uma perspectiva pragmatista ou economicista. Graff (1995) reúne suficientes evidências históricas de que não necessariamente os graus de alfabetismo da população estão correlacionados ao desenvolvimento ou à modernização econômica. Se tomamos o caso do Brasil contemporâneo, é também inegável que uma grande parte dos postos de trabalho disponíveis exige nenhuma ou pouquíssimas habilidades de leitura e escrita. $O$ fato de que, apesar disso, a alfabetização e a escolarização elementar venham se expandindo, tanto no Brasil como em escala mundial, atesta que a funcionalidade dessas competên- 
cias excede a dimensão econômica e deve ser considerada, com igual ou maior ênfase, na sua relação com as dimensões políticas e culturais do desenvolvimento social.

É indiscutível o fato de que a alfabetização é uma necessidade para todos os indivíduos que integram sociedades modernas, provendoIhes meios de desempenhar várias atividades associadas ao trabalho ou ao âmbito doméstico, meios de melhorar o exercício efetivo de direitos e responsabilidades de cidadania. $O$ valor do acesso à leitura e à escrita reside também no fato de serem meios para se aprender outras habilidades, ampliando a autonomia das pessoas com relação ao auto-aprendizado e à educação continuada. Requerimentos sociais dessa magnitude invalidam a restrição da alfabetização aos rudimentos da leitura e da escrita. Não se podem conceber competências básicas como necessariamente simples ou rudimentares; o básico está relacionado ao fato de se tratar de competências que todas as pessoas, em princípio, deveriam dominar, sejam elas simples ou complexas.

\section{A definição do conceito e os problemas da pesquisa}

Esses fatos justificam o interesse teórico e prático de se investigar as competências da população com relação ao uso da leitura e da escrita, colocando, ao mesmo tempo, uma série de dificuldades com relação ao estabelecimento de critérios para a delimitação do fenômeno, condição necessária para que possa ser abordado cientificamente, ou mesmo para que sirva ao estabelecimento de metas educacionais suficientemente definidas. Em documento preparado para a Unesco, Soares (1992) expõe uma boa síntese dos problemas conceituais envolvidos na mensuração e na avaliação do alfabetismo. Analisando três estratégias normalmente utilizadas para dimensionar o domínio de competências a ele relacionadas em populações - avaliações nos sistemas escolares, levantamentos censitários e surveys domiciliares - a autora discute as vantagens e as limitações dos critérios estabelecidos em cada um dos casos.

Com relação às avaliações realizadas nos sistemas de ensino, Soares aponta a vantagem de se poder abordar a alfabetização como processo, uma vez que, tomando dados de diferentes séries, se podem estabelecer padrões de progresso com relação à leitura e à escrita. Observa, entretanto, que isso só é possível em países onde os sistemas de ensino são su- 
ficientemente organizados e homogêneos, permitindo corresponder a assistência a uma série a um certo nível de desempenho. Não seria esse o caso em países subdesenvolvidos, onde os sistemas são desorganizados e comportam desigualdades extremadas. Entretanto, o problema crucial encontrado nas avaliações em sistemas escolares reside no fato de que, assim procedendo, limitamo-nos ao estudo do alfabetismo escolarizado, ou seja, às práticas de leitura, de escrita e de cálculo tal como exercitadas e avaliadas pela escola, o que não corresponde aos usos extra-escolares que se podem fazer dessas habilidades (Heath 1986; Cook-Gumperz 1991).

Em pesquisas censitárias, é inevitável que se estabeleça um critério único distinguindo os alfabetizados dos analfabetos, o que pode ser feito considerando a informação fornecida pelos entrevistados, baseada em seus próprios critérios de avaliação, ou tomando como indicador um determinado número de anos de estudo (ou séries completadas). No primeiro caso, o que se procura averiguar é o domínio mais rudimentar da leitura e da escrita; ainda assim, é difícil que os entrevistados mantenham o mesmo critério ao se auto-avaliarem, ou ainda que eximam suas avaliações de distorções condicionadas por atitudes de humildade ou vergonha. Visando superar essas limitações e, ainda, considerar como alfabetizados indivíduos com níveis de competência não tão rudimentares, analistas de dados censitários tomam como indicador um certo número de anos de estudo. Já observamos que os critérios para estabelecer a quantidade de anos suficiente estão longe de ser objetivos; além disso, há estudos que apontam a não-linearidade da correlação entre grau de escolaridade e domínio de competências como leitura, escrita e cálculo (Infante 1994b; Oecd 1995). Por um lado, nada garante que as pessoas escolarizadas tenham de fato adquirido tais habilidades ou que as tenham mantido depois de um certo tempo; por outro, é possível desenvolver as mesmas habilidades por meio de experiências extra-escolares. Nos países subdesenvolvidos, também a heterogeneidade dos sistemas de ensino prejudica a validade de tal critério.

Finalmente, Soares aponta os surveys domiciliares especialmente delineados para tal fim como o meio mais acurado de dimensionar o grau e a qualidade do alfabetismo em populações. Em tais pesquisas podem ser considerados tanto o domínio dos indivíduos sobre a leitura, a escrita ou o cálculo quanto os tipos de práticas sociais em que utilizam essas habilidades. Ainda que pesquisas dessa natureza possam fornecer uma visão mais compreensiva do fenômeno, elas não estão isentas dos problemas advindos da dificuldade de definir o alfabetismo ou abarcar toda a 
multiplicidade de suas dimensões. A esse respeito, Soares recomenda que as pesquisas sobre o alfabetismo estabeleçam definições operacionais, esclarecendo os conceitos implícitos, o tipo de competências que se pretende avaliar e os contextos nos quais se espera que elas se manifestem.

Uma abordagem latino-americana

Desde 1994, pesquisadores brasileiros vêm participando de uma pesquisa sobre esse tema em âmbito latino-americano, promovida pela Orealc - Oficina Regional de Educación para América Latina y Caribe --, órgão da Unesco. A coordenadora do referido projeto é Isabel Infante, pesquisadora chilena especialista em alfabetização e educação de adultos, que já realizou o piloto sobre o tema, envolvendo quatro países da região e agora coordena este que envolve sete países: Argentina, Brasil, Chile, Colômbia, México, Paraguai e Venezuela. ${ }^{3}$ No marco teórico do projeto de pesquisa, Isabel Infante (1994) evidencia a intencionalidade de superar a perspectiva economicista da problemática do analfabetismo funcional. Toma como base recomendações aprovadas em Consulta Técnica Ibero-americana sobre Analfabetimo Funcional (Lodoño 1991), relacionadas à multiplicidade das dimensões sociais a que o analfabetismo se relaciona: com o trabalho, com a ciência e tecnologia, com a organização e participação popular e com a cultura. Outro aspecto enfatizado é a relevância do estudo no contexto das reformas educativas que vêm sendo realizadas em toda a América Latina, uma vez que, sendo a escola a principal agência de alfabetismo em nossas sociedade, a qualidade e a pertinência das aprendizagens que ela promove constituem fatores essenciais na promoção de uma melhor inserção dos grupos populares no âmbito profissional, nas organizações sociais e na produção cultural.

Com relação aos problemas envolvidos na medição de habilidades lingüísticas, Infante chama a atenção para a importância de considerar não apenas os resultados que se podem medir por meio de testes padronizados, como também os processos que dão origem a esses resultados. Como solução metodológica, propõe a combinação de técnicas quantitativas - que ajudam a dimensionar as capacidades e as carências de uma dada população, com vistas à definição de políticas de amplo alcance - e técnicas qualitativas - que revelam tanto as estratégias de que lançam mão os jovens e adultos para resolver problemas da vida diária, quanto suas próprias representações sobre suas competências e 
necessidades. Esse segundo enfoque é especialmente útil para o aprimoramento pedagógico de programas educativos desenvolvidos para responder às necessidades detectadas.

Procurando sintetizar as linhas gerais do projeto, que integra dimensões inovadoras com outras que dão continuidade tanto à etapa piloto quanto a outras pesquisas sobre o tema realizadas em outras regiões, Isabel afirma:

En líneas generales, la presente propuesta [...] intenta evaluar los logros de los adultos en habilidades de lectura, escritura y matemáticas necesarias para la vida diaria en ámbitos influidos por la modernidad, relacionándolos com participación social y laboral y com percepción de sus competencias sociales y laborales. Sin embargo, introduce dos aspectos básicos que enriquecen el estudio: las estratégias que emplean los adultos en la resolución de situaciones de problemas generados por el uso del código de la escritura (tanto en general, como en la descodificación de lo escrito y en las operaciones matemáticas) y el significado de la situación de analfabetismo funcional desde la perspectiva de los involucrados en ella. (Infante 1994)

A pesquisa realizada no município de São Paulo (Haddad \& Ribeiro 1997) pautou-se por essas proposições teórico-metodológicas. Nela, procurou-se equilibrar as ênfases nos enfoques quantitativo e qualitativo e, principalmente, buscar as relações de complementariedade entre eles. Por esse motivo, insistiu-se na inclusão de tarefas simuladas de leitura e escrita também na etapa qualitativa, proposta inicialmente para todos os países, mas depois suspensa por problemas operacionais, de modo a reunir mais elementos para uma compreensão integral do objeto de estudo. O objetivo da etapa quantitativa foi dimensionar o fenômeno do alfabetismo funcional, bem como levantar suas principais características. Para tanto, foram utilizados um teste de leitura e um questionário, aplicados a uma amostra aleatória, representativa da população do município de São Paulo entre 15 e 54 anos, composta de mil pessoas. Na segunda etapa, de natureza qualitativa, visou-se o aprofundamento da compreensão do fenômeno, com a realização de entrevistas semi-estruturadas e a proposição de tarefas simuladas a uma subamostra intencional de 26 pessoas.

O teste aplicado na etapa quantitativa continha tarefas simuladas envolvendo operações de leitura e cálculo que podem ser requeridas em contextos cotidianos. Os testes abarcaram três domínios de habilidade: compreensão de textos em prosa (notícias de jornal e textos instrucionais), com- 
preensão de textos esquemáticos (tabelas e gráficos) e compreensão de textos com informação numérica, esse último implicando também a realização de cálculos matemáticos básicos a partir de dados contidos em impressos. Esses domínios de habilidade, estabelecidos a partir do tipo de material de leitura e do tipo de processamento de informação envolvido, vêm sendo utilizados em vários surveys nacionais e internacionais. ${ }^{4} \mathrm{~A}$ análise dos dados obtidos por meio desse teste resultou no estabelecimento de quatro níveis de habilidade para cada um desses domínios, que puderam ser caracterizados a partir do tipo de tarefa que cada grupo era capaz de responder numa certa proporção de casos. O questionário aplicado nessa etapa continha itens sobre o perfil demográfico da população estudada, seu background familiar, sua história escolar, seu nível socioeconômico, sua participação social, seus usos da escrita, sua leitura e seu cálculo no trabalho e na vida diária, sua participação em programas de educação de jovens e adultos, além de uma escala de autopercepções sobre competências sociais e profissionais. Desse conjunto de informações foi identificada uma série de variáveis da população correlacionada com seus níveis de alfabetismo.

Nas entrevistas, realizadas na etapa qualitativa junto à subamostra, investigaram-se os usos que os sujeitos fazem da leitura, da escrita e da matemática, os significados atribuídos a essas práticas, as estratégias utilizadas para enfrentar situações que exigem essas habilidades e suas expectativas com relação à educação de adultos. Quanto às tarefas propostas na etapa qualitativa, o foco da análise concentrou-se nos processos de resolução no contexto de interação com a pesquisadora, objetivando também reunir elementos que complementassem a interpretação dos resultados dos testes. O quadro abaixo sintetiza, comparativamente, as especificidades da metodologia utilizada em cada uma das etapas da pesquisa:

\section{QUADRO 1 - Procedimentos metodológicos nas abordagens quantitativa e qualitativa}

\begin{tabular}{|c|c|}
\hline Etapa quantitativa & Etapa qualitativa \\
\hline $\begin{array}{l}\text { - entrevista estruturada (aplicação } \\
\text { de questionário) }\end{array}$ & - entrevista semi-estruturada \\
\hline $\begin{array}{l}\text { - resolução de tarefas simuladas } \\
\text { individualmente, com análise es- } \\
\text { tatística dos resultados em termos } \\
\text { de erro e acerto }\end{array}$ & $\begin{array}{l}\text { - resolução de tarefas simuladas em } \\
\text { interação com o pesquisador, com } \\
\text { análise exploratória do processo de } \\
\text { resolução e das representações } \\
\text { do sujeito sobre a tarefa }\end{array}$ \\
\hline
\end{tabular}


O principal objetivo de se reunir e analisar informações sobre os tipos e graus de alfabetismo do conjunto da população jovem e adulta, confrontados com aqueles exigidos pela sociedade contemporânea em diferentes contextos, foi oferecer uma base de referências para orientar políticas educacionais tanto para o ensino regular como para a educação de adultos em várias de suas modalidades formais e não formais. Informações sobre habilidades relacionadas ao alfabetismo requeridas pelo mercado de trabalho, pela economia doméstica, por práticas de cuidado da saúde, pelo lazer, pela participação comunitária ou participação no debate dos temas de interesse público são valiosas para o desenvolvimento curricular da educação básica, para a orientação de programas de qualificação profissional e também para o estabelecimento de políticas culturais voltadas aos jovens e adultos. A realização dessa pesquisa como parte de um projeto latino-americano, que reuniu dados de outras sete metrópoles do continente, amplia a sua relevância, abrindo a possibilidade de se estudar o fenômeno numa perspectiva comparativa, situando o caso brasileiro com relação a outros países com os quais o Brasil projeta estreitar alianças econômicas, políticas e culturais e com os quais comparte muito de sua herança cultural.

\section{Notas}

1. Alguns autores brasileiros têm utilizado o neologismo "letramento", com o mesmo sentido. Como Soares (1995), preferimos aqui empregar "alfabetismo", porque já dicionarizado e também por manter a mesma raiz do termo "alfabetização", relativo ao ato de ensinar ou disseminar o ensino da leitura e da escrita.

2. Recommendation concerning the standardization of educational statistcs, publicado em 1958 pela Unesco, traz a definição "A person is literate who can with understanding both read and write a short statement of his everyday life", Revised recommendation concerning the standardization of educational statistcs, de 1978, traz sua nova definição "A person is functionally literate who can engage in all those activities in which literacy is required for effective functioning of his group and community and also for enabling him to continue to use reading, writing and calculation for his own and the community's development" - apud Soares (1992, pp. 8-9).

3. A participação brasileira na pesquisa promovida pela Orealc realizou-se no âmbito do Programa de Pesquisa Ciência e Tecnologia, Qualificação e Produção, coordenado pelo Cedes e financiado pelo PCDT/CNPq e pela Finep. 
Tendo travado contato com este estudo em sua fase piloto, Vanilda Pereira Paiva promoveu sua inclusão no projeto por ela coordenado, "Qualificação e Inserção Não Industrial e Medição de Skills entre Adolescentes e Adultos", parte do referido programa de pesquisa. A execução do trabaIho ficou a cargo de Ação Educativa - Assessoria, Pesquisa e Informação, que participou desde o início da equipe latino-americana, enviando contribuições para a construção dos instrumentos, analisando suas versões preliminares e, finalmente, adaptando-os para o contexto em que seriam aplicados no Brasil: o município de São Paulo.

4. Em Literacy: Profiles of America's young adults (Kirsch \& Jungeglut 1986), No single measure (Wickert 1989) e na versão em língua inglesa da publicação que divulga os resultados do International Adult Literacy Survey (Oecd 1995), esses domínios são denominados prose literacy, document literacy e quantitative literacy; na versão em língua francesa da última publicação, os termos utilizados são: compréhension de textes suivis, compréhension de textes eschématiques, compréhension de textes au contenu quantitatif.

\title{
Functional literacy: Conceptual and methodological references for research
}

\begin{abstract}
The article discusses functional literacy as a concept referring to the condition of people or societies that use written language. It recovers the origins of the concept and its several applications, even those that are divergent. It also points out the principal theoretical and methodological problems implicated in the research on the theme. It affirms most current tendencies that consider literacy as multidimensional and the importance of considering practical and ideological contexts in which uses of writing and reading occur. It describes, in general terms, the methodological options of a study that is taking place in Latin America in which a group of Brazilian researchers are participating.
\end{abstract}

\section{Bibliografia}

ANDERSON, Richard. Becoming a nation of readers: The report of the Commission of Reading. Washington: The National Institute of Education, 1995. 
CASTELL, S; LUKE, A. \& MACLENNAN. "On defining literacy". In: CASTELL, S. LUKE, A. \& EGAN, K. (eds.). Literacy, Society and Schooling: $A$ reader. Cambridge, Cambridge University Press, 1986.

COOK-GUMPERZ, J. A construção social da alfabetização. Porto Alegre, Artes Médicas, 1991.

FLECHA, Ramón et al. Estudi sobre l'analfabetisme funcional a Catalunya. Barcelona, Generalitat de Catalunya, 1993.

GRAFF, Harvey. Os labirintos da alfabetização. Porto Alegre, Artes Médicas, 1995.

HADDAD, Sérgio \& RIBEIRO, Vera M. Alfabetismo funcional no município de São Paulo. São Paulo, 1997. (mimeo)

HEATH, Shirley. "Critical factors in literacy development". In: CASTELL, S.; LUKE, A. \& EGAN, K. (eds.). Literacy, Society and Schooling: A reader. Cambridge, Cambridge University Press, 1986.

INFANTE, Isabel. Educacion, comunicacion y lenguaje: Fundamentos para la alfabetización de adultos en América Latina. México, CEE - Centro de Estudos Educativos, A.C., 1983.

"O analfabetismo funcional na América Latina: Algumas características a partir de uma pesquisa regional." In: Encontro latino-americano sobre educação de jovens e adultos trabalhadores. Brasília, Inep, 1994a.

Investigación regional sobre analfabetismo funcional. Santiago, Unesco/Orealc, 1994b.

KIRSCH, I. \& JULGEBLUT, A. Literacy: Profiles of America's young adults final report of the National Assessment for Educational Progress. Princeton, Educational Testing Service, 1986.

LODOÑO, L. El analfabetismo funcional. Un nuevo punto de partida. Lima, Tarea, 1991.

Oecd - Organization for Economic Co-operation and Development. Literacy, Economy and Society: Results of the First International Adult Litercay Survey. Paris, Oecd, 1995.

SCRIBNER, S. \& COLE M. The psychology of literacy. Cambridge, Havard University, 1981. 
SOARES, Magda. B. "Língua escrita, sociedade e cultura: Relações, dimensões e perspectivas." Revista Brasileira de Educação, (0) 516, Belo Horizonte, Anped, set./out./nov./dez. 1995.

Literacy assessment and its implications for statistical measurement. Paris, Unesco, 1992.

STREET, Brian. Literacy in theory and practice. Cambridge, Cambridge University Press, 1984.

WICKERT, Rosie. No single measure: A survey of australian adult literacy. Sydney, Commonwealth of Australia, 1989. 